\title{
THE REBOUND PHENOMENON IN ACUTE RHEUMATIC FEVER
}

\author{
BY \\ K. S. HOLT \\ From the Department of Child Health, the University of Sheffield
}

(RECEIVED FOR PUBLICATION JULY 2, 1956)

Children suffering from acute rheumatic fever are usually treated with the hormone preparations, cortisone and A.C.T.H., or with salicylates. Almost always symptoms are rapidly alleviated and clinical signs of activity subside. In a number of cases discontinuance of treatment when the disease process seems to be quiescent is followed by an apparent recrudescence. This feature has become known as the rebound phenomenon but an extensive search of the literature has failed to reveal any detailed study of it.

\section{Definitions}

There is a divergence of opinion with regard to the significance of the terms 'relapse' and 'rebound'. Illingworth, Burke, Doxiadis, Lorber, Philpott and Stone (1954) suggested that a relapse occurs if the criteria suggested by Jones (1944) for the diagnosis of rheumatic fever are again satisfied. Bywaters and Dixon (1952) defined a relapse as a return of the disease after its apparent cessation and a rebound as " no more than a special type of relapse which we define as the transient worsening of the disease process '. A distinction is made by Kelley, Adams and Good (1953) between a laboratory rebound, as revealed solely by such tests as the erythrocyte sedimentation rate, the $\mathrm{C}$-reactive protein and the serum mucoproteins, and a clinical rebound in which there may be fever, tachycardia and subjective symptoms. It is likely that the laboratory rebound, clinical rebound and relapse merely represent different degrees of the same process.

\section{Incidence}

Interest in the rebound phenomenon increased when cortisone and A.C.T.H. were employed in the treatment of rheumatic fever. Several writers have implied that the rebound is a feature of hormone therapy. That a rebound may be seen after salicylate treatment has been emphasized by Massell (1950, 1953), Fischel, Frank and Ragan (1952), Stollerman (1953), Illingworth et al. (1954), Kuttner
(1954) and McEwen (1954), and Still (1927) wrote: 'I have several times observed that ... the discontinuance of the salicylate has been followed after a few days by a further rise of temperature.' When the hormone preparations were still scarce the doses employed were small and the courses of treatment were short. There is no doubt that many of the rebounds then observed occurred in incompletely treated cases. It was hoped that when adequate treatment was given the rebound would not occur, but this has not proved to be so.

It is difficult to know how frequent are rebounds, for the reported series of cases vary considerably with regard to composition and management. Kelley (1952) reported nine rebounds in 18 children treated with A.C.T.H. intramuscularly. Two-thirds of the cases reported by Rowe, McKelvey and Keith (1953) treated with hormones showed a rebound. Kelley et al. (1953) found that out of 61 cases treated with A.C.T.H. 24 showed a laboratory and 11 a clinical rebound. In the large series of cases studied jointly by the Medical Research Council and the American Council on Rheumatic Fever (1955) just over a quarter of the hormonetreated cases showed a rebound of the sedimentation rate. Harris, Needleman, Harris and Friedman (1956) reported that they found the incidence of the rebound to be similar in cases treated with A.C.T.H. and with cortisone. One-third showed a rebound with clinical features and one-third of the sedimentation rate alone. On the basis of these reports, between a quarter and two-thirds of cases of acute rheumatic fever treated with cortisone or A.C.T.H. may be expected to show a rebound, somewhat more than half of these being laboratory rebounds.

The incidence of the rebound in the salicylatetreated cases is even more uncertain. Massell (1950, 1953) described the rebound in salicylate-treated cases as 'an occasionally observed phenomenon'. Done, Ely, Ainger, Seely and Kelley (1955) reported on 21 children treated with salicylates in varying amounts and for varying periods of time but until 
the sedimentation rate had been normal for at least a week. Eight of these cases showed a rebound. Warren, Higley and Coombs (1946) said that approximately $40 \%$ of their cases treated with small doses of salicylates showed a rebound compared with about $60 \%$ of the cases given large doses. In the study by the Medical Research Council and the American Council on Rheumatic Fever (1955) only $2 \cdot 8 \%$ of the salicylate-treated cases showed a rebound of the sedimentation rate compared with $25 \%$ of the cortisone- and $26.6 \%$ of the A.C.T.H.treated cases. Rebounds of temperature occurred in $14.3 \%$ of the cortisone-treated cases compared with $5.9 \%$ of the A.C.T.H.- and $4.2 \%$ of the aspirin-treated cases. The higher percentage in the cortisone-treated case appears to be due to an appreciably lower incidence of fever at the time of stopping therapy than in the other groups. A number of the hormone-treated cases had a rebound of the sedimentation rate and not of the temperature, while some of the salicylatetreated cases had a rebound of temperature without elevation of the sedimentation rate. These results suggest that relatively low doses of salicylates may be associated with a low incidence of the rebound. This is not supported by the finding of Warren et al. (1946) that approximately $40 \%$ of their cases treated with salicylates in low doses showed a rebound and the fact that earlier writers such as Still (1927), who gave sodium bicarbonate with salicylates thereby greatly reducing the blood salicylate level, apparently witnessed the rebound phenomenon quite frequently. Two sections of the joint Anglo-American study have been reported separately and the salicylate-treated cases in these groups showed a considerably higher incidence of rebound than in the joint report. Rowe et al. (1953) said that in the salicylate group 'slightly over a third had a rebound of the sedimentation rate'. Houser, Clark and Stolzer (1954) reported the numbers of cases in the three treatment groups showing a rebound within three weeks of stopping therapy. Fifty-one of 61 cases treated with aspirin showed a rebound as compared with 38 of 42 given A.C.T.H. and 43 of 45 given cortisone. This is only a very slightly lower incidence in the salicylate group than in the hormone groups.

\section{Duration}

Most writers have suggested that the rebound is necessarily of short duration and that extension beyond this period warrants further therapy. Keith and Neill (1951) suggested that the duration of the rebound in hormone-treated cases was such that it brought the total span of the increased sedimentation rate to approximately the same duration as was observed in children treated with salicylates. According to Bunim, Kuttner, Baldwin and McEwen (1952), the rebound usually subsides within 20 days. Massell (1950), writing about rebounds in salicylatetreated cases, said that the fever subsided in three or four days. Dorfman, Smull, Bergenstal, Howard, Muller, Oleson and Senz (1951) found the intensity and duration of the rebound to be highly variable. Massell (1954) described two groups of cases, in the first of which the rebound subsided within a few days to a week, while in the other group the manifestations continued for weeks or months. Harris et al. (1956) wrote that 'rebound phenomena generally began within a week of the termination of the course of hormone treatment, rose to a peak of severity within another week and then in the great majority of instances declined and disappeared spontaneously'.

\section{Aetiology}

Several hypotheses have been put forward to account for the rebound phenomenon. Bywaters and Dixon (1952) suggested that the rebound represented the period of inhibition of the pituitaryadrenal system caused by exogenous hormones. Kroop (1954) also thought that relative adrenal insufficiency was the cause of the rebound. This theory does not explain the occurrence of the rebound in salicylate-treated cases. McEwen (1954) criticized this hypothesis and reported a failure to find changes in the excretion of steroids at the time of the rebound.

Another suggestion is that the action of both salicylates and the hormones is purely suppressive. This has been examined and criticized by Fischel et al. (1952). If this hypothesis were correct then the shorter the duration of therapy the higher would be the incidence of the rebound, the greater its severity, and the longer its duration. There is no evidence of the truth of this hypothesis. Another argument against this hypothesis is that if it were correct the interval between stopping therapy and the appearance of the rebound would be fairly constant for a given form of treatment as it would correspond to the time required for the particular drug to be eliminated from the body, but this is not observed. A third suggestion is that the drugs, in addition to any suppressive action, also influence the inflammatory response of the host. This view is supported by Fischel et al. (1952). The rebound is thus presented as the residues of rheumatic activity which in most cases quickly subsides. If this hypothesis is applied to the large series of cases reported by the Medical Research Council and the 
American Council on Rheumatic Fever (1955), in which approximately a quarter of the hormonetreated cases showed a rebound of the sedimentation rate as compared with about $3 \%$ of the aspirintreated group, it would appear that aspirin had been more effective than the hormones in shortening the course of the disease. This is a conclusion which many would be unwilling to accept.

\section{Management}

If the theories as to the cause of the rebound lead to unsatisfactory conclusions the recommendations as to management are even more contradictory. McEwen (1955) stated 'its (the rebound's) recognition is of practical importance because it is not an indication for further treatment'. On the other hand, Barnes, Smith, Slocumb, Polley and Hench (1951) wrote: 'We are convinced now that these flares of the disease could and should have been prevented.' Stollerman (1953) said: 'If a "relapse" or a "rebound" of clinical or laboratory evidence appears treatment should be reinstituted for at least an additional six weeks or longer.' It seems likely that most workers give further treatment if the rebound persists for longer than a specified period or if the rebound includes clinical features of appreciable intensity. Massell (1950) and McEwen (1954) suggested giving small doses of salicylates for a short time after the end of the main course of treatment to reduce the incidence of the rebound. Graham (1955) felt that salicylates were more suitable than hormones for the control of the rebound.

The uncertainty about the nature and treatment of the rebound prompted the study of a number of cases of rheumatic fever which is reported below.

\section{Present Study}

Material. Between January, 1949, and December, 1955,110 children were admitted to the Sheffield Children's Hospital under the care of Professor R. S. Illingworth, all of them satisfying the diagnostic criteria (Table 1) of Jones (1944).

Eighteen cases formed a small portion of the joint study organized by the Medical Research Council and the American Council on Rheumatic Fever (1955). Four received A.C.T.H., seven cortisone and seven aspirin. The doses of the drugs were as stated in the report and the duration of treatment in all cases was six weeks. The remaining cases were in investigations carried out in the Department of Child Health of the University of Sheffield and have been reported elsewhere (Illingworth et al., 1954; Holt, Illingworth, Lorber, Rendle-Short and Gibson, 1954). Others will be reported shortly. Ten children were given salicylates in low doses and
55 children received high doses of salicylates. Two children were given cortisone alone, eight had cortisone and low doses of salicylates together, and 17 received cortisone and high doses of salicylates. When salicylates were used in high doses the dose was adjusted to maintain a serum salicylate level of 30 to $40 \mathrm{mg}$. per $100 \mathrm{ml}$. Salicylates in low doses consisted of $5 \mathrm{gr}$. four times a day to children weighing less than $50 \mathrm{lb}$. and $10 \mathrm{gr}$. three times a day to children over $50 \mathrm{lb}$. Cortisone was given by mouth in the following dosage: $200 \mathrm{mg}$. per day for four days, $100 \mathrm{mg}$. per day for the remainder of the first three weeks, $75 \mathrm{mg}$. per day for the next two weeks and $50 \mathrm{mg}$. per day thereafter until the end of treatment. The treatment in these cases was continued until there was no clinical evidence of activity and the sedimentation rate had been normal for three consecutive weekly readings or for a maximum period of three months. In the 18 cases in the joint study the sedimentation rate was determined by the Wintrobe method and a reading of over $20 \mathrm{~mm}$. in one hour (uncorrected) was considered to be abnormal. In the other cases the sedimentation rate was determined by the micro Westergren technique and the normal uncorrected reading was considered to be $10 \mathrm{~mm}$. in one hour or less. Throat swabs were taken initially and shortly after the completion of therapy as a routine and at any other time if indicated clinically.

\section{Observations}

A rebound phenomenon was considered to have occurred if within four weeks of stopping treatment there were any clinical symptoms or signs suggesting activity or if the sedimentation rate became raised again when at the time of stopping treatment these features had been absent or normal. Four of the 110 cases still showed evidence of activity when treatment was stopped and are not considered in the detailed analysis below. Seventy-two cases did not show a rebound whereas 34 cases did (Table 1).

A rebound occurred in 11 out of 36 children

TABLE 1 NUMBER OF CASES, NATURE OF TREATMENT AND

\begin{tabular}{|c|c|c|c|c|}
\hline \multirow{2}{*}{ Form of Therapy } & \multirow{2}{*}{$\begin{array}{c}\text { Total } \\
\text { Number } \\
\text { of } \\
\text { Cases }\end{array}$} & \multirow{2}{*}{$\begin{array}{l}\text { Cases Still } \\
\text { Active at } \\
\text { End of } \\
\text { Therapy }\end{array}$} & \multicolumn{2}{|c|}{ Rebound Cases } \\
\hline & & & Sepsis & Othet \\
\hline High salicylates & 55 & 1 & 0 & 22 \\
\hline $\begin{array}{l}\text { High salicylates and } \\
\text { cortisone }\end{array}$ & 17 & 0 & 1 & 6 \\
\hline $\begin{array}{l}\text { A.C.T.H. alone } \\
\text { Low salicylates and }\end{array}$ & 13 & 2 & 3 & 0 \\
\hline $\begin{array}{c}\text { cortisone } \\
\text { Low salicylates }\end{array}$ & $\begin{array}{r}8 \\
17\end{array}$ & $\begin{array}{l}0 \\
1\end{array}$ & $\begin{array}{l}\mathbf{0} \\
\mathbf{0}\end{array}$ & 1 \\
\hline Totals & 110 & 4 & 4 & 30 \\
\hline
\end{tabular}


receiving hormones $(30.6 \%)$, and in 23 out of 70 children not receiving hormones $(33 \%)$. On the other hand the dosage of salicylates in children not receiving hormones bore a strong relationship to the frequency of the rebound phenomenon. There was a rebound in 22 out of 54 cases $(40.7 \%)$ receiving high doses, as compared with one out of 16 cases $(6 \cdot 2 \%)$ receiving salicylates in low dosage.

In Fig. 1 are shown the nature and the time of

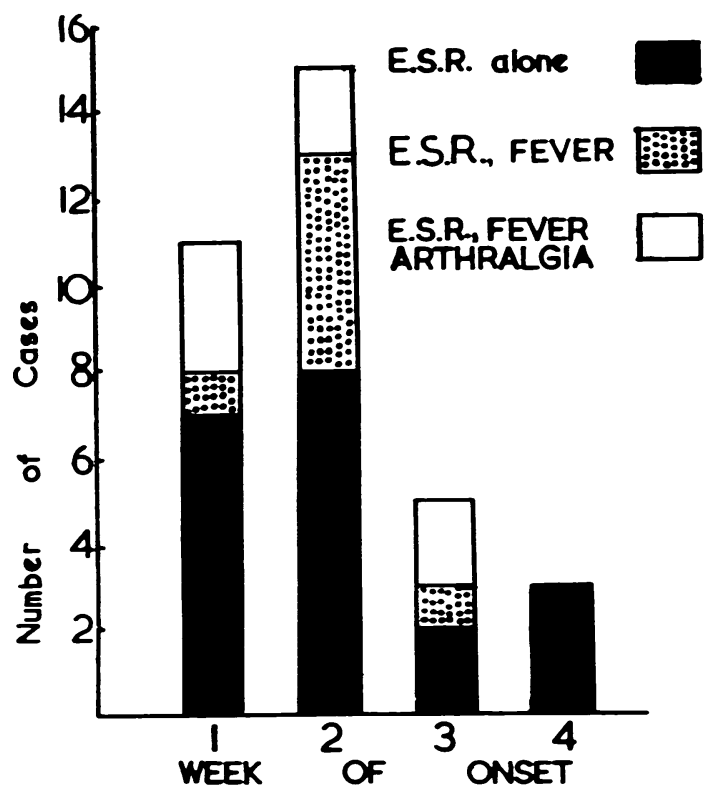

Fig. 1.-Type of rebound selected to time of onset.

onset of the rebound. Twenty cases showed elevation of the sedimentation rate alone, seven cases also had a raised temperature, and seven had joint pains, one of whom showed a transient pericardial friction rub. Twenty-six of the 34 rebounds occurred within two weeks of stopping treatment. Severe rebounds occurred no sooner after discontinuance of treatment than mild ones. The nature of the treatment did not appear to affect the time of onset of the rebound or its character.

\section{Sepsis}

In four of the 34 children exhibiting a rebound there was a sufficiently severe septic lesion to account for it. The rebound settled when the sepsis cleared. One of these children had a paronychia, one an injection abscess, and two had a dental abscess. All four had had hormone therapy. In three of these only the sedimentation rate rose after discontinuance of specific treatment. In the fourth case there was a rise of the sedimentation rate together with a raised temperature. It was not possible from the nature or the time of onset of the rebound to distinguish these four cases associated with sepsis from the remaining 30 cases of apparently true rheumatic rebounds.

\section{Streptococei}

When it had been observed that a number of the rebounds were associated with sepsis a thorough search was made for other possible infective factors. It was then found that more of these children, as compared with those not exhibiting a rebound, had throat swabs positive for $\beta$ haemolytic streptococci in the immediate post-treatment period (Table 2 ).

TABLE 2

NUMBER OF CASES WITH THROAT SWABS POSITIVE FOR $\beta$ HAEMOLYTIC STREPTOCOCCI AT END OF THERAPY

\begin{tabular}{|c|c|c|c|}
\hline Group & $\begin{array}{c}\text { H. Streptococcus } \\
\text { Present }\end{array}$ & $\begin{array}{c}\text { H. Streptococcus } \\
\text { Absent }\end{array}$ & $\begin{array}{c}\text { Not } \\
\text { Known }\end{array}$ \\
\hline $\begin{array}{l}\text { No Rebound } \\
\text { Rebound .. }\end{array}$ & $\begin{array}{l}4 \\
9\end{array}$ & $\begin{array}{l}55 \\
15\end{array}$ & $\begin{array}{r}13 \\
6\end{array}$ \\
\hline
\end{tabular}

In the rebound group nine children had positive cultures, 15 children had negative cultures and in six children the results were not known. In the group without a rebound four children had positive cultures, 55 had negative cultures and in 13 children the results were not known. The difference is of statistical significance. When the $\chi^{2}$ test is applied, using Yates modification for small numbers and using the numbers of cases where the result of the cultures is known in the two groups, it is found that $\chi^{2}=7.6$ and $p=<0.01$.

None of these children had symptoms or signs of a throat infection, but it appears that pathogenic streptococci in the throat may be associated with the rebound phenomenon. As six of the nine cases with positive cultures were known to have had negative throat cultures during the treatment period, it is possible that the streptococci were acquired from ward cross-infection.

\section{Sex and Age}

It was found to be convenient to study the cases in two groups, those aged under 10 years and those aged 10 to 14 years. In Table 3 are shown the

TABLE 3

NUMBER OF CASES IN RELATION TO AGE AND SEX

\begin{tabular}{|c|c|c|c|c|}
\hline \multirow[b]{2}{*}{ Group } & \multicolumn{2}{|c|}{ Boys } & \multicolumn{2}{|c|}{ Girls } \\
\hline & 4-9 years & $10-14$ years & 49 years & $10-14$ years \\
\hline No rebound & 18 & 22 & 21 & 11 \\
\hline Rebound & 7 & 8 & 4 & $\left(\begin{array}{c}11 \\
\left(73 \cdot 3^{\bullet} .\right)\end{array}\right.$ \\
\hline
\end{tabular}


number of cases in each age and sex group who had a rebound. The proportion of teenage girls in the rebound group $(73.3 \%)$ is more than twice that in the group without a rebound $(34.4 \%)$. This difference is statistically significant $\left(\chi^{2}=4 \cdot 7\right.$ and $\mathrm{p}=<0.05$ ). It seems possible therefore that teenage girls are particularly liable to show a recrudescence of the disease following the cessation of treatment. Eight of the 11 girls in this group showed clinical features in addition to elevation of the sedimentation rate. One of the girls was menstruating at the time but this did not appear to be related to the rebound.

\section{Duration of Illness}

Another factor thought to increase the incidence of the rebound was a relatively long duration of illness before treatment. The cases were divided into two groups-those with a history of five weeks or less and those in which the illness had been present for between six and 12 weeks before treatment. The numbers of cases in these two groups is shown in Table 4. The proportion of cases of

TABLE 4

NUMBER OF CASES IN RELATION TO DURATION OF ILLNESS

\begin{tabular}{l|c|c}
\hline & \multicolumn{2}{c}{ Duration of Illness } \\
\cline { 2 - 3 } \multicolumn{1}{c}{ Group } & $0-5$ weeks & $6-12$ weeks \\
\hline $\begin{array}{l}\text { No rebound } \\
\text { Rebound }\end{array}$ & $\cdots$ & 57 \\
\hline
\end{tabular}

long duration in the rebound group $(43.3 \%)$ is more than twice that in the group without a rebound $(20.8 \%)$. This difference is statistically significant $\left(\chi^{2}=5 \cdot 38, \mathrm{p}<0.05\right)$.

These three factors, $\beta$ haemolytic streptococci in the throat, early adolescence and an illness of long duration, inevitably overlapped, so that in one-third of the cases more than one of the three factors was present. One or more of these factors was present in 24 of the 30 rebound cases, but no explanation could be found in the remaining cases. There did not seem to be any relationship between the cause of the rebound and its nature and time of onset.

\section{Clinical Features}

The incidence of the various clinical features of rheumatic fever at the start of treatment was compared in the rebound group and in the group without a rebound (Fig. 2). The only statistically significant difference is the lower incidence of arthritis in the rebound group. The observed difference between the percentages in the two groups is greater than twice the standard error of the differences. Arthritis is a relatively short-lived manifestation of rheumatic fever and is less commonly observed in cases with a long history. There is a greater number of cases of long duration in the rebound group and this may account for the lower incidence of arthritis.

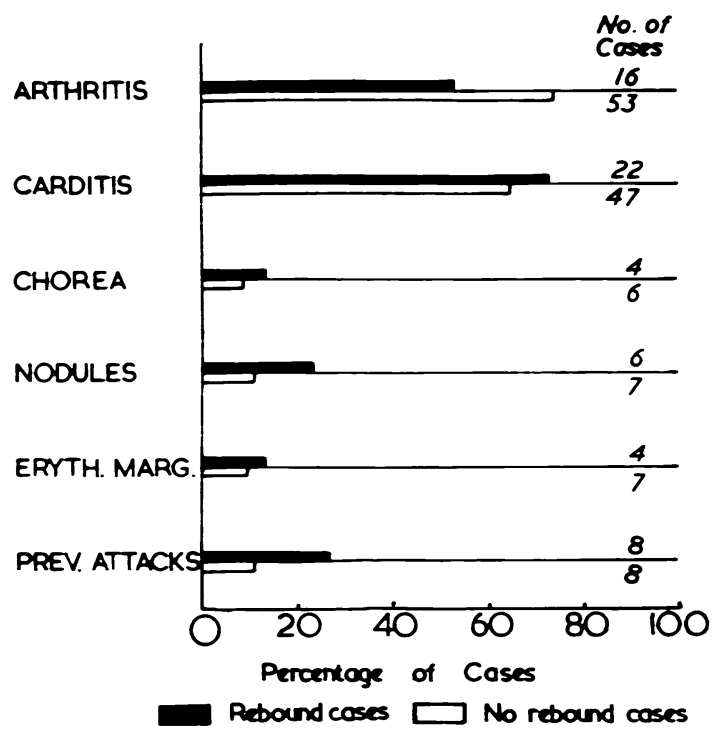

Fig. 2.-Incidence of clinical features.

\section{Duration of Therapy}

In Table 5 is depicted the duration of treatment in the rebound and no-rebound groups. Seventeen of the rebound cases $(56.7 \%)$ required treatment for seven weeks or more, a considerably higher proportion of the cases than in the other group where 27 cases $(37.5 \%)$ received treatment for long periods. This difference is not due to any difference in the forms of treatment employed in the two groups. If a single treatment group is considered, such as the one receiving salicylates in high dosage, the same differences occurred. In the 54 children receiving salicylates in high dosage 22 showed a rebound and of these $14(63.6 \%)$ had been treated

TABLE 5

NUMBER OF CASES IN RELATION TO DURATION OF THERAPY

\begin{tabular}{|c|c|c|}
\hline \multirow[b]{2}{*}{ Group } & \multicolumn{2}{|c|}{ Duration of Therapy } \\
\hline & Up to 6 weeks & Over 7 weeks \\
\hline $\begin{array}{l}\text { No rebound } \\
\text { Rebound }\end{array}$ & $\begin{array}{l}45 \\
13\end{array}$ & $\begin{array}{l}27(37 \cdot 5 \%) \\
17(56 \cdot 7 \%)\end{array}$ \\
\hline
\end{tabular}


TABLE 6

TREATMENT OF REBOUND AND SECOND REBOUNDS

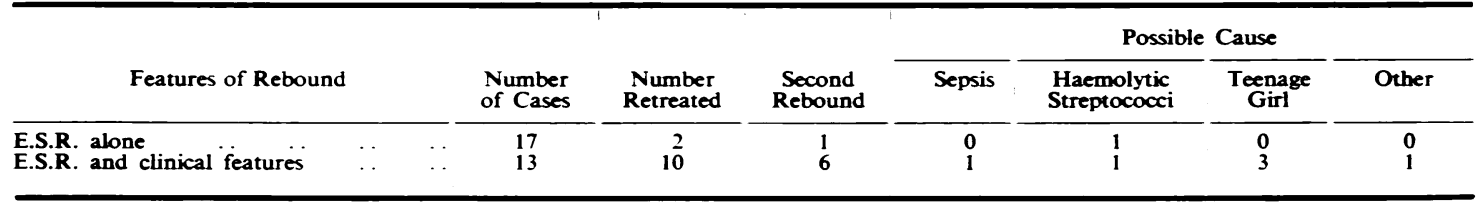

All second rebounds were of E.S.R. alone.

All second courses of treatment were the same as the original courses.

for seven weeks or longer. Of the 32 children not showing a rebound $15(46.9 \%)$ had been treated for long periods. It appears that the factors tending to produce the rebound also tend to prolong the duration of therapy.

\section{Progress of the Rebound Cases}

Of the 30 true rheumatic rebound cases, 18 settled spontaneously but 12 cases, two with elevation of the sedimentation rate alone and 10 with clinical features, required a second course of therapy, either because the criteria of Jones (1944) were satisfied again or because the rebound persisted for more than two weeks (Table 6). The second course of treatment was identical with the original course and was continued until there were no clinical signs of activity and the sedimentation rate had been normal again for three consecutive weekly readings. Of the 12 cases retreated, seven had a second rebound of the sedimentation rate alone. One was associated with sepsis, a dental abscess developing in a child receiving cortisone; in two $\beta$ haemolytic streptococci appeared in the throat and three of the other four second rebounds occurred in teenage girls.

An attempt was made to evaluate the effect of the rebound upon the long term prognosis. In Table 7 is shown the incidence of subsequent attacks

TABLE 7

PROGNOSIS

\begin{tabular}{|c|c|c|}
\hline & No rebound & Rebound \\
\hline $\begin{array}{l}\text { Total number of cases } \\
\text { Subsequent attacks } \\
\text { Heart damage }\end{array}$ & $\begin{array}{l}72 \\
7\left(9 \cdot 7^{\circ}\right) \\
15(20 \cdot 8 \%)\end{array}$ & $\begin{array}{l}30 \\
4(13 \cdot 3 \circ) \\
6(20 \cdot 0 \%)\end{array}$ \\
\hline
\end{tabular}

of rheumatic fever and of permanent heart damage in the two groups. There is no appreciable difference in the incidence of these two features in the two groups, and it appears, therefore, that the occurrence of the rebound does not necessarily indicate a more serious prognosis. The mean duration of follow-up in the rebound group is $2 \cdot 26$ years as compared with $2 \cdot 23$ years in the group without a rebound.

\section{Discussion}

In this study the rebound phenomenon occurred in cases of rheumatic fever treated with hormone preparations in no greater frequency than in cases treated with salicylates. Septic lesions appeared to play an important part in the production of the rebound in the hormone-treated group. After 38 courses of hormone therapy (36 initial and two second courses) sepsis was seen five times, in $13 \%$ of courses of treatment. Dental abscesses accounted for three of these five instances. It is well known that the use of cortisone and A.C.T.H. may be followed by the development of septic lesions and that these may develop insidiously and be difficult to detect because of the hosts' altered inflammatory response. It is surprising, considering the numbers of cases of rheumatic fever that are treated with hormones, that more comment has not been made on this point. Possibly Massell, Warren, Sturgis, Hall and Craige (1950) were considering sepsis when they wrote in reference to the rebound following A.C.T.H., that 'a few cases of fever in which other factors may have played a role are omitted from the discussion'. Brøchner-Mortensen (1952) reported that after treatment for some length of time six of their 18 patients showed various septic complications; four had a urinary infection, two had adenitis and one showed suppuration of an old wound. Hecht, Shelden, Nolke, Hofstra and West (1956) reported 122 cases treated with hormones and wrote that although they were alert to the possibility of masked infection, none was found. Two of the hormone-treated cases with septic lesions reported in the present study were in the joint U.S.-U.K. investigation. This is not mentioned in the published report of the Medical Research Council and the American Council on Rheumatic Fever (1955) but it would seem possible that some of the relatively large numbers of rebounds in that study were due to masked infection. In any child with rheumatic fever treated with hormones and developing a rebound the possibility of a masked infection should be considered.

That rheumatic fever follows a $\beta$ haemolytic streptococcal infection is generally accepted and 
Catanzaro, Stetson, Morris, Chamovitz, Rammelkamp, Stolzer and Perry (1954) have shown that the important element is the presence in the throat and nasopharynx of living streptococci for several days. It is also generally accepted that pathogenic streptococci can invade the upper respiratory tract and there survive and multiply for long periods without apparently producing any marked local or general response in the host. It is not surprising, therefore, that some cases of rebound are related to the presence of streptococci in the throat. Ziegra and Kuttner (1951) found that a number of cases of rebound showed a rise of the anti-streptolysin $O$ titre. It is said that none of these cases had intercurrent streptococcal infections but the evidence for this statement is not given. Unless cultures were taken on all cases, it may be that some were harbouring streptococci without showing clinical symptoms. Greenman, Weigand, Mateer and Danowski (1955), however, reported that 16 of 53 patients acquired 3 haemolytic streptococci during their period in hospital and that none of these had a recrudescence of activity. In the present study pathogenic streptococci were associated with the rebound on 11 occasions (nine initial and two second rebounds). Four of these, which occurred early in the series, had not received antibiotic prophylaxis. In the other seven children oral penicillin was given routinely as a prophylactic measure but only one child received penicillin intramuscularly at the beginning. It is possible that the streptococci were never properly eliminated in these cases. A point against the suggestion that the streptococci persisted from the original infection is that negative cultures had been obtained earlier in seven of the 11 cases. This may have been due to a difficulty in isolating the organism which demands specialized techniques (Catanzaro et al. (1954). For practical purposes, however, both aspects must be emphasized: streptococci must be eliminated initially by adequate doses of penicillin intramuscularly and reinfection reduced as much as possible by the continued exhibition of oral penicillin. If the child with rheumatic fever is admitted to a hospital dealing with acute admissions the risk of cross infection will be high and it is probably advisable to give, during this period, larger doses of oral penicillin than are commonly employed. Greenman et al. (1955) suggested that cortisone reduced their patients' ability to ward off infections and that larger amounts of penicillin were needed for prophylaxis. Much can be achieved by the careful placing of the patient well away from any others with streptococcal infections in the ward. Before the advent of chemoprophylaxis Duckett Jones (1943) wrote as follows:
- It is advisable that as soon as the patient has recovered sufficiently he be moved to an atmosphere where he is exposed less frequently to infection. especially of the respiratory tract.'

For some time now it has been our impression that the "older" girls responded less readily to treatment and showed recrudescences of activity more frequently than the other children. This difference is borne out by the present investigation. StuartHarris (1956) has suggested that the response of teenage girls resembles that seen in adult patients.

It is difficult to understand why a relapse is more likely in children who have been ill for a longer time than others before treatment is begun. Dorfman et al. (1951) found that the rebound was more severe in patients with chronic active disease, whilst Greenman et al. (1955) found that the rebound was much more frequent in those cases with a history of more than six weeks than in those of shorter duration.

It follows from the above remarks that when a rebound occurs a septic focus should be sought, and the nose and throat swabbed for haemolytic streptococci. If the rebound lasts for more than about a fortnight, it seems likely that a further course of treatment should be given, especially in an adolescent girl. We do not as yet know for certain how much harm the rebound does, if any, but it would seem reasonable to check rheumatic activity in the hope that cardiac damage would be reduced.

The high incidence of rebounds in children treated with salicylates in high dosage as compared with that of children treated with low dosage is of special interest. It is only in part accounted for by a higher incidence of haemolytic streptococci in the throat, as shown by throat swabs, in the group treated with salicylates in high dosage, and by a slightly greater proportion of adolescent girls similarly treated. It is possible that salicylates in low dosage are less effective in treatment than in higher dosage.

\section{Summary}

One hundred and ten children with acute rheumatic fever completed their treatment and 34 were found to show a rebound within four weeks of stopping treatment. Twenty had elevations of the sedimentation rate alone while 14 showed clinical features as well.

There were no more rebounds in children treated with hormones than there were in those treated with salicylates, but there were more rebounds in those treated with salicylates in high dosage than there were when a low dosage was used.

It was shown that the incidence of rebounds was related to four factors: (1) The presence of septic 
lesions in hormone-treated cases; (2) the presence of $\beta$ haemolytic streptococci in the throat; (3) early adolescence in girls; (4) a long illness before institution of treatment. These factors were present in 28 of the 34 cases. In the remaining children there were no known related factors.

Professor R. S. Illingworth indicated the importance of a study of the rebound phenomenon and throughout has encouraged and criticized the work most generously. Drs. J. L. Emery, J. Lorber and T. J. Rendle-Short have given helpful advice and criticism during the preparation of this paper.

Dr. G. H. Jowett, Ph.D., and Miss Wendy M. Gibson, B.A., rendered valuable statistical assistance.

\section{Addendum}

Since this paper was written another case treated with cortisone has developed a rebound due to dental sepsis. We are so impressed by the importance of dental infection in these children that in future all children with rheumatic fever will have a routine dental examination.

\section{REFERENCES}

Barnes, A. R.. Smith, H. L., Slocumb, C. H., Polley, H. F. and Hench, P. S. (1951). Amer. J. Dis. Child., 82. 397

Brechner-Mortensen, K. (1952). Acta med. scand., Suppl., 266, p. 299.

Bunim, J. J., Kuttner, A. G., Baldwin, J. S. and McEwen, C. (1952). J. Amer. med. Ass., 150, 1273.

Bywaters, E. G. L. and Dixon, A. St. J. (1952). Quart. J. Med., n.s. $21,307$.

Catanzaro, F. J., Stetson, C. A., Morris, A. J.. Chamovitz, R., Rammelkamp, C. H., Stolzer, B. L. and Perry, W. D. (1954), Amer. J. Med., 17, 749.
Done, A. K., Ely, R. S., Ainger, L. E., Seely, J. R. and Kelley, V. C. (1955). Pediatrics, 15, 522.

Dorfman, A., Smull, K., Bergenstal, D. M., Howard, R., Muller, R.. Oleson. D. and Sens, E. (1951). Ibid., 8. 603.

Fischel, E. E., Frank, C. W. and Ragan, C. (1952). Medicine (Baltimore), 31, 331.

Graham S (1955) Brit med J. 2731.

Greenman, L. Weigand, F. A. Mateer, F. M. and Danowski, T. S. (1955). Amer. J. Dis. Child., 89, 442.

Harris. T. N., Needleman, H. L., Harris, S. and Friedman, S. (1956). Pediatrics, 17, 29.

Hecht, M. S., Shelden, W. E., Nolke, A.. Hofstra, D. and West. E. (1956). J. Pediat.. 48. 300

Holt. K. S., Illingworth. R. S.. Lorber, J., Rendle-Short, J. and Gibson, Wendy M. (1954). Lancet, 2, 1144.

Houser H. B. Clark. E. J and Stolzer, B. L (1954). Amer. J. Med. 16. 168 .

Illingworth. R. S.. Burke, J., Doxiadis, S. A., Lorber. J., Philpott. M. G. and Stone, D. G. H. (1954). Quart. J. Med., n.s. 23. 177.

Jones, T. D. (1943). The Epidemiology of Rheumatic Fever, p. 116. Metropolitan Life Insurance Co.. New York. (1944). J. Amer. med. Ass., 126. 481.

Keith. J. D. and Neill, C. A. (1951). Canad. med. Ass. J., 64. 193.

Kelley, V. C. (1952). Amer. J. Dis. Child., 84, 151.

Adams, F. H. and Good, R. A. (1953). Pediatrics, 12. 607.

Kroop, I. G. (1954). N.Y. St. J. Med., 54, 2699

Kuttner, A. G. (1954). In Nelson's Textbook of Pediatrics, 6th ed.. p. 936. Philadelphia and London.

McEwen, C. (1954). Amer. J. Med., 17. 794.

(1955). Med. Clin. N. Amer., 39, 353

Massell, B. F. (1950). Ibid., 34, 1419 .

- (1953). Ibid., 37. 1215.

- (1954). New Engl. J. Med.. 251. 183.

-, Warren, J. E., Sturgis, G. P., Hall. B. and Craige, E. (1950). Ibid., 242. $641,692$.

Medical Research Council and the American Council on Rheumatic Fever, Joint Report (1955). Brit. med. J., 1, 555.

Rowe, R. D., McKelvey, A. D. and Keith, J. D. (1953). Canad. med. Ass. J., 58, 15.

Still, G. F. (1927). Common Disorders and Diseases of Childhood. 5 th ed., p. 556. London.

Stollerman, G. H. (1953). Holt, L. E. \& Mcintosh. R.. Textbook of Pediatrics, 12th ed., p. 823 . New York.

Stuart-Harris. C. H. (1956). Personal communication. Heart J.. 32, 311.

Ziegra, S. R. and Kuttner, A. G. (1951). Amer. J. med. Sci., 222. 516. 